\title{
Analytical and Experimental Modeling of Heat and Mass Transfer in Electrodynamic Apparatuses
}

\author{
Burdo Oleg ${ }^{1}$, Svetlichnyj Pavel ${ }^{2}$, Mordynskiy Vsevolod $^{3}, \underline{\text { Sirotyuk Ilya }}^{4}$
}

1. Doctor of Technical Sciences, Professor, Head of Department of Processes, Equipment and Energy Management, Odessa National Academy of Food Technologies, UKRAINE, Odessa, Kanatna st, 112, Email: poem.onaft@gmail.com

2. Ph.D., Associate Professor, Department of Processes, Equipment and Energy Management, Odessa National Academy of Food Technologies, UKRAINE, Odessa, Kanatna st., 112, E-mail: poem.onaft@gmail.com

3. Ph.D., Associate Professor, Department of Processes, Equipment and Energy Management, Odessa National Academy of Food Technologies, UKRAINE, Odessa, Kanatna st., 112, E-mail: poem.onaft@gmail.com

4. Graduate student, Assistant of the Department of Processes, Equipment and Energy Management, Odessa National Academy of Food Technologies, UKRAINE, Odessa, Kanatna st, 112,

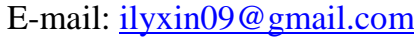

\begin{abstract}
The hypothesis of possibility of electromagnetic energy sources using for address energy delivery directly to grout moisture is offering. The schemes of fuel energy conversion during traditional thermal concentration technology and innovation plant based on the electromagnetic energy generators are presented.
\end{abstract}

Keywords - nanotechnologies, microwave field, mechanodiffusion effect, math modeling, address energy delivery.

\section{Introduction}

Traditional technologies of drying and evaporation of chemical, pharmaceutical and food industries do not meet the modern requirements of resource-energy efficiency. The processes associated with the dehydration of raw materials are characterized by common serious problems: high energy consumption and quality of the finished product, especially for thermolabile raw materials. An independent problem of evaporators is the regulation of the finished product final concentration. This problem is due to the fact that with increasing concentration of the solution, its viscosity and the thickness of the boundary thermal layer increase. The result is a decrease of the steam generation intensity, thermal deterioration of raw materials in the boundary layer. The task of the work is to substantiate the prospects of fundamentally new methods of organizing the dehydration processes in the electrodynamic apparatuses developed in the ONAFT.

\section{Research results}

Electrodynamic apparatus designs implement the scientific and technical hypothesis proposed by the authors: "the processing of raw materials, which contain polar molecules, with an electromagnetic field will lead to the selective energy action directly on polar molecules, partial transfer of liquid into the vapor phase, increase of pressure in the volume of raw materials and initiate a specific hydrodynamic flow, the power of which can exceed the traditional diffusion flux by orders of magnitude ".

The task is to develop a mathematical model for the interaction of a microwave electromagnetic field with a liquid in a capillary 1 (Fig. 1). The energy supply $\mathrm{N}$ is volume at the PG of the second kind. The modeling is based on the first law of thermodynamics and the Fourier-Kirchhoff equations, which reflect the thermal interactions between the elements of the 
system under consideration. Since the work done by the body, in accordance with the problem posed, is zero, the first law of thermodynamics for this case will be written in the form:

$$
Q_{s t}+Q_{V}=\Delta U
$$

where $\mathrm{Q}_{\mathrm{st}}$ is the amount of heat received (or given) by the body through the surface of the capillary $(\mathrm{S})$; $\mathrm{Q}_{\mathrm{v}}$ is the amount of heat that is absorbed by the solution from electromagnetic energy sources; $\Delta \mathrm{U}$ - change of internal energy.

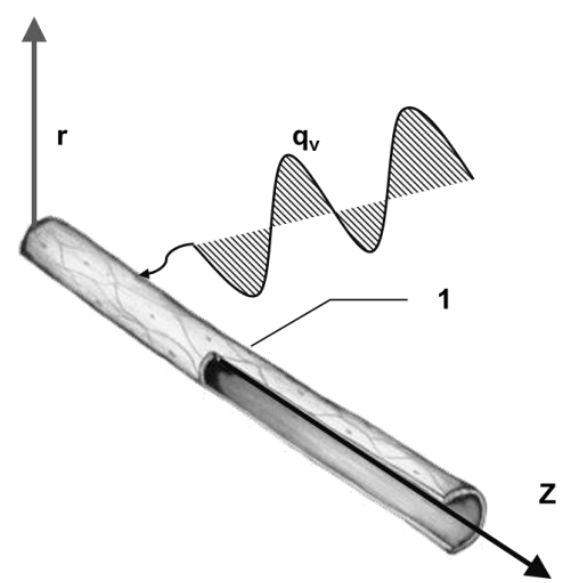

Fig.1. Statement of the modeling problem.

Experimental studies were carried out at the stand (Fig. 2), the main units of which are: evaporator chamber, chamber body, raw material, vacuum pump, condenser (CD), water cooler, a condensate collector (CC) and a scale.

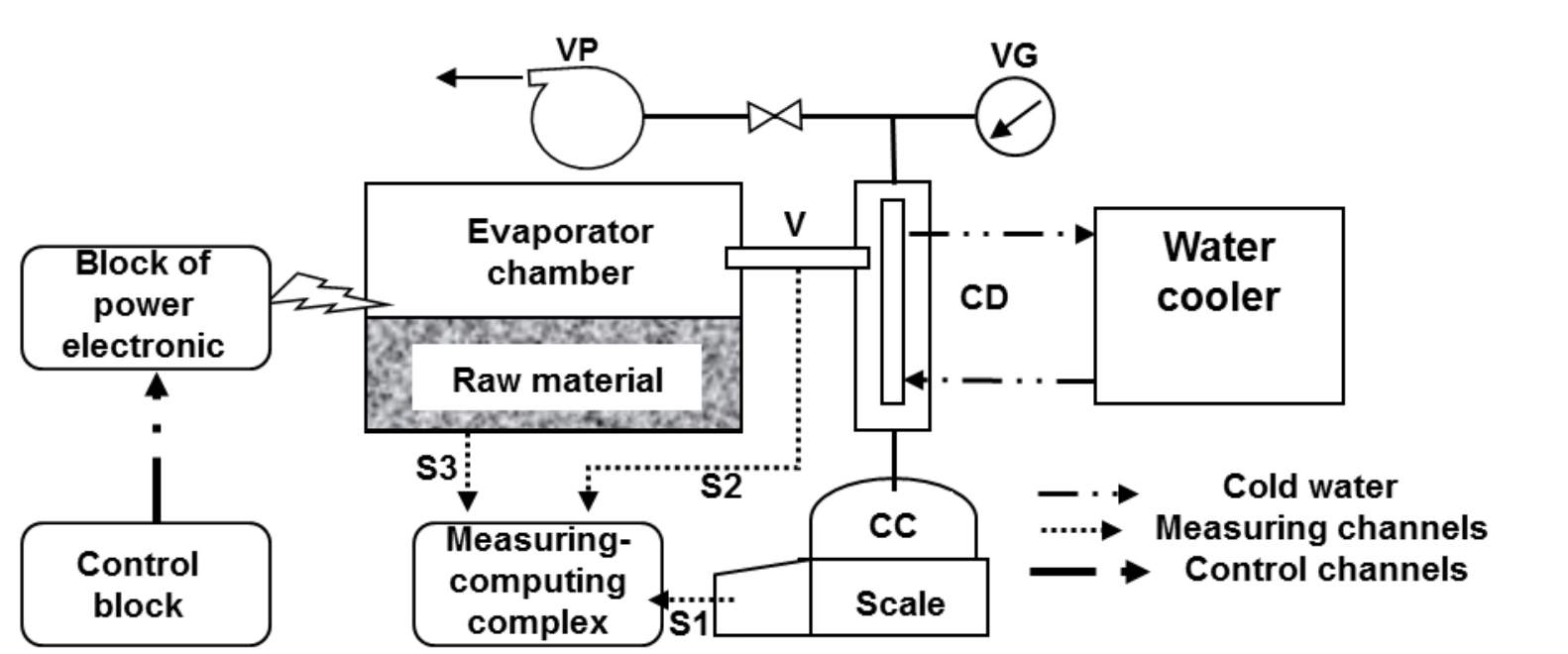

Fig.2. Scheme of the experimental stand.

In the experiments, the following were recorded: power consumption, vacuum, product temperature and steam output. The current values of $\mathrm{W}$ were determined from the indications of electronic scales (by the mass of the condensate in the collection). Thus, the yield of steam was determined with high accuracy. Operating temperatures did not exceed $50{ }^{\circ} \mathrm{C}$. Typical dependencies are shown in Fig. 3. 


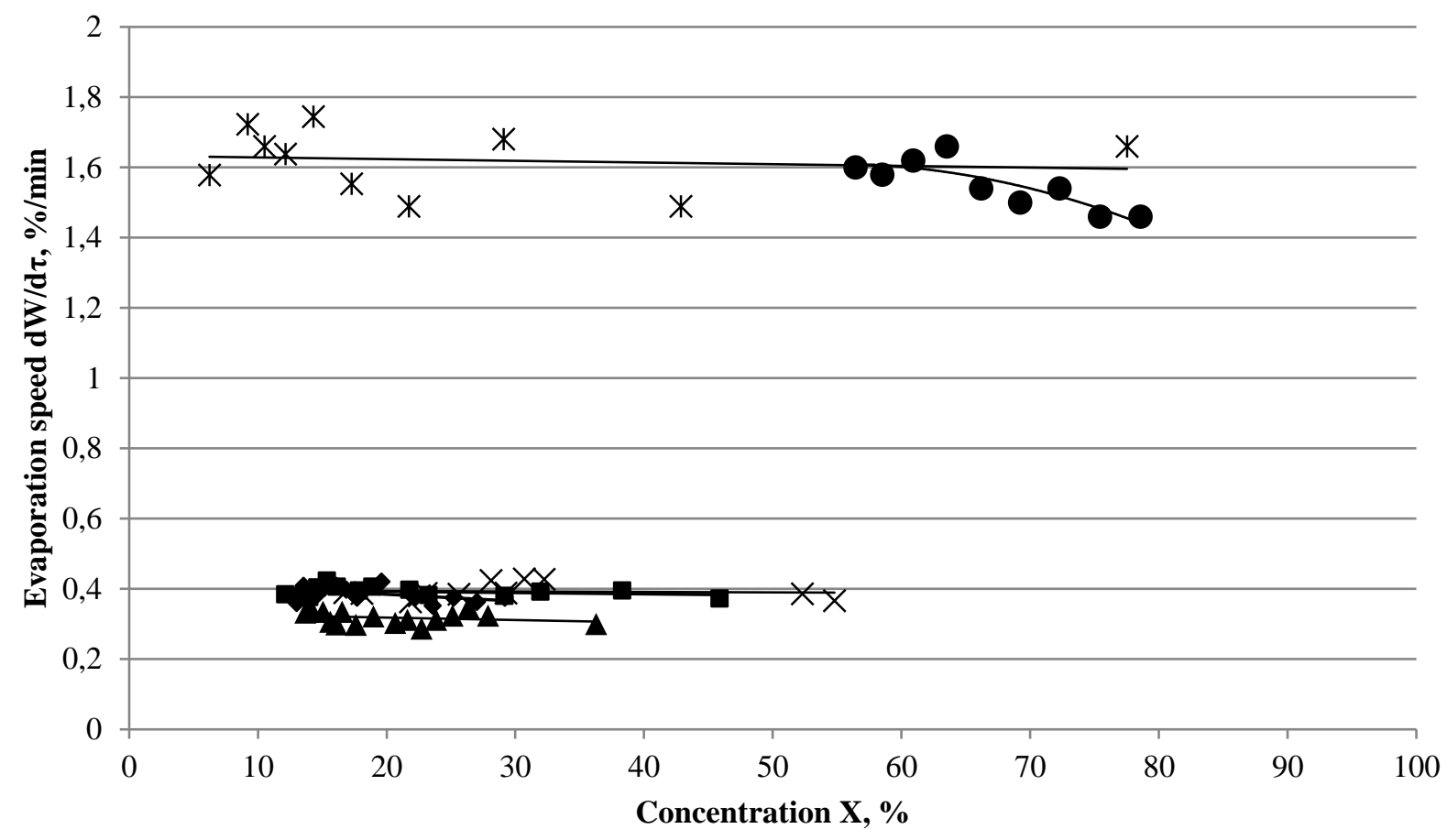

$\boldsymbol{\Delta}, \boldsymbol{X}, \bullet, \mathbf{\square}$ - watercontaining homo- and heterogeneous systems $\boldsymbol{*}$,

- alcoholcontaining heterogeneous composition

Fig.3. Lines of vaporization rate in electrodynamic apparatus.

\section{Conclusion}

In the conditions of EMF it is possible to initiate a specific flow from the volume of raw material. This effect was recorded for the first time; it was given the name "mechanodiffusion effect". The organization of such a flow, the driving force of which is the pressure difference, allows you to remove moisture in the form of mist during drying, that is, not convert all the moisture into steam, significantly reduce both energy costs and the duration of the process. The result of such processes can be: increase in the yield of target components, the transition to a solution of valuable components that were not removed by traditional methods (aromatic and flavor complexes, compounds).

\section{References}

[1] O. Burdo, I. Sirotyuk, Yu. Levtrinskaya, S. Terziev "Technologies of targeted energy action in processes of homogeneous and heterogeneous food systems dehydration". Scientific works. National university of food technologies. vol. 24, №5. p. 99-108, 2018.

[2] O. Burdo, I. Sirotyuk, Yu. Alhuri, Yu. Levtrinskaya, "Microwave Energy, as an Intensification Factor in the Heat-Mass Transfer and the Polydisperse Extract Formation", Problemele energeticii regionale, vol. 1, is. 36, p. 58-71, 2018. DOI: 10.5281/zenodo.1217259 